\title{
A Consumption Based Human Development Index and The Global Environmental Kuznets Curve*
}

\author{
Raghbendra Jha, RSPAS \\ Australian National University
}

\author{
K.V. Bhanu Murthy \\ University of Delhi
}

\begin{abstract}
We extend the analysis of Jha and Murthy (2003) to relate consumption to environmental degradation (conceived of as a composite) within a cross-country framework. We use the method of Principal Components Analysis (PCA) to construct an Environmental Degradation Index (EDI) for each country and global environmental degradation (GED) as the sum of the EDI's. We then identify outliers and influential observations among both the environmental and consumption related variables. Canonical Discriminant analysis is then used to classify development classes along environmental lines. We then estimate a simultaneous equation model to analyze the pattern of causation between per capita income, consumption and environmental degradation. We estimate a Global Environmental Kuznets curve (GEKC) as a relation between EDI ranks and ranks of the consumption-based EDI. A cubic representation is most appropriate with high-consumption countries contributing excessively to GED and middleconsumption countries slightly less. Low-consumption countries are contributing insignificantly to GED. Finally we present an alternative consumption-based Human Development Index to UNDP's income-based Human Development Index. We then compare the ranking of countries according to the consumption-based HDI ranks with their ranking according to their EDI. Two sets of data drawn from the Human Development Report (HDR) UNDP(2000)) are used in the analysis. One relates to the environment and the other to developmental variables. For the formation of a composite index that would enable the estimation of a GEKC for 174 countries, we used cross-sectional data used in the HDR. The two main contributions of this paper are to build a consumption based HDI and to estimate a Global EKC based on consumption. A simultaneous equations model explains the causal structure that is responsible for Global Environmental Degradation. Further, with Canonical Discriminant Analysis it has been shown that GED does not have geo-physical basis but an anthropogenic basis. As a part of the system of equations a Global Consumption Function has been estimated that displays interesting results. In net, the paper attempts to establish that a certain 'type of development' that characterizes high consumption countries is primarily responsible for Global Environmental Degradation.
\end{abstract}

\section{All correspondence to:}

Prof. Raghbendra Jha,

Australia South Asia Research Centre

Division of Economics

Research School of Pacific and Asian Studies

The Australian National University

CANBERRA ACT 0200

Australia

Telephones +61261254482 or 61252683

Facsimile: + 61261250443

Email: r.jha@anu.edu.au

\footnotetext{
* We are grateful to the John D. and Catherine T. MacArthur Foundation for financial support.
} 


\section{Introduction}

The interdependence between levels of economic development and environmental degradation ${ }^{1}$ has typically been explained by the Environmental Kuznets Curve (EKC). Some commentators argue that the EKC, which is purported to be an inverted $U$ - shaped curve between select pollutants and per capita income (PCI), supports the contention that so long as developing countries are below the threshold of development, their growth would only increase the Global Environmental Degradation (GED). Since developed countries lie beyond the peak of the EKC, further economic growth would only lower GED. A corollary is that developing countries must sacrifice growth and developed countries should enhance growth for the sake of a healthy global environment. This argument, would thus achieve global inter-temporal efficiency by fostering global atemporal (spatial) inequity.

On the other hand, we believe that "the applicability of the notion of sustainability has ultimately got to be universal and refer to the indefinite future" and must be related to consumption (Jha and Bhanu Murthy (2000) p.3). ${ }^{2}$ In particular, Jha and Whalley (2001) have argued that the notion of the EKC (typified as a relation between per capita incomes and select pollutants as in the extant literature) for any given country is tenuous, at best. ${ }^{3}$

One problem with extant EKC formulations is that the analysis is confined to a few select pollutants and to a narrow measure of economic development (per capita income). In particular, there has been little effort to relate per capita income (or some other broad measure of economic development) to a composite index of environmental degradation in a cross section of countries. Jha and Murthy (2003) have estimated a Global EKC (GEKC), for 174 countries using a more complete measure of economic development than per capita income - the Human Development Index ${ }^{4}$ (HDI) ranks of countries- and relate these to the levels of environmental degradation of these countries as captured in a composite Environmental Degradation Index (EDI). We established that this GEKC assumes a cubic form with

\footnotetext{
${ }^{1}$ It is so called because Kuznets (1955) had found a similar inverted - $U$ shaped relationship between income growth and income inequality.

${ }^{2}$ A number of definitions of sustainability are discussed here, ibid. p. 4- 8.

${ }^{3}$ For a further review of empirical studies on EKC see Jha and Murthy (2003).

${ }^{4}$ As is well known, the HDI rank is an ordinal index.
} 
developed countries contributing the lion's share of GED. This paper was a forerunner of the present paper. Our attempt here is to shift the focus in the growth-environment debate ${ }^{5}$ towards consumption.

This paper is organized as follows. Section II recounts the notion of global environmental degradation whereas section III evaluates the existing consumption- based approaches. The fourth lays out the methodology for our analysis and data sources and section V reports the results. Section VI concludes.

\section{Global Environmental Degradation}

When analyzing GED, a number of issues have to be addressed: does it arise from local phenomenon restricted to individual countries? Is income per capita an appropriate basis for tracing the EKC? Is GED a consequence of geophysical phenomenon or is it anthropogenic? What are the specific causative factors responsible for GED? What is the structure of causal factors? Why is GED a composite? What are the implications of these questions for methodology? ${ }^{6}$ A considered response to these questions would involve a fresh examination of the empirical form and analytical content of the GEKC as a manifestation of GED. In this respect, if the intention is to study the composite phenomenon, all factors responsible for GED must be included in the analysis.

There seems to be a consensus that the following four factors are primarily responsible for environmental degradation: a) Pollution - of various types; b) Lack of bio-diversity; c) Waste- toxic and non-toxic; and d) Erosion of the natural resource base due to phenomenon like deforestation, depletion of fresh water resources, paper consumption, etc. Levels of these indictors or the like, define the 'state of the world' in an entropic context. In the pristine natural state there is no entropy. Hence, there is no degradation or disorganization of the 'state of the world'. Entropy occurs as unwarranted human activity takes place. As long as anthropogenic activity is in consonance with and commensurate to the 'state of the world' there is no environmental degradation. Our basic hypothesis is that excessive and lop-sided consumption patterns of human consumption are the most fundamental

\footnotetext{
${ }^{5}$ For a review of the growth-environment debate see Jha and Murthy (2003).

6 "Trans-boundary pollution has been overemphasized in literature, as the cause of GED. So it must be pointed out that it is responsible only for the spread of pollution and would nevertheless remain only one of the factors responsible for GED, not the entire 'cause'.
} 
'cause' of entropy. Especially, extreme events cause severe degradation. Therefore, it is important to identify outliers and influential observations and to measure their contribution to global environmental degradation.

GED occurs as a result of an accumulation of local phenomenon. Often GED has been treated as a geographic and natural phenomenon and not explicitly as an economic phenomenon, more particularly one that arises out of a certain 'type of economic development'. GED is a composite because such phenomena mutually influence each other. For instance, excessive paper consumption would result in deforestation, which would cause a fall in water resources and a growth in CO2 levels, which would then cause global warming, soil degradation and denudation, which would adversely affect bio-diversity and so on. Therefore, we would prefer to call them indicators of GED. In our understanding, the composite of GED is caused by a certain type of development.

A maintained hypothesis of the present paper is that global environmental problems are rooted in local phenomena. If this were true then the GEKC would arise within a collective crosssectional (cross-country) framework. A major issue with regard to the EKC is that extant studies have taken for granted the conceptual phenomenon of its empirical basis. GED is an economic phenomenon being 'caused' by certain 'latent' factors, related to economic development. We conceptualize GED as a "composite" since it would be simplistic to assume otherwise and conceive of this as a conglomerate of many factors that may be acting as vectors in different directions, with the resultant vector having a certain central tendency (the grand mean). A secular increase (both temporally and spatially) in this conglomerate of factors would 'cause' entropy and would be indicative of the phenomenon of GED. The composite of GED is in this sense, 'caused' by another composite of economic development, with each of the composites appropriately weighted. It is important to both conceive of and measure this composite and relate it to the 'type of development' that leads to degradation.

At the empirical level, these indicators involve both simultaneity and multicollinearity. The regression approach (to the EKC) has this limitation of multicollinearity as well as the need to assume normality. In contrast, Principal Components Analysis (PCA) performs well in relation to removing these weaknesses of regression analysis. PCA is based on a linear transformation of the 'regressors' 
such that they are orthogonal to each other by design. Hence, the information contained in the all points in the event space is retrievable. None of it is treated as a random error (that is orthogonal to the best fit line). Secondly, the normality assumption is not essential. In the real world, where there are wide differentials amongst countries, and between individual effects of indicators, such an assumption is dispensable. Thirdly, with such a dispersed set of outcomes, PCA is ideally suited because it maximizes the variance rather than minimizing the least square distance. For these reasons we chose PCA.

\section{Existing Consumption-based approaches}

While it is common to relate environmental degradation to PCI certain studies have argued that factors related to production are the possible reasons behind environmental degradation (Grossman \& Krueger, 1992, 1994; Radetzki, 1992; Panayotou, 1993; Grossman, 1995). ${ }^{7}$ Nonetheless, there have been a few studies (e.g. Ehrlich and Holdren, 1971) that have attempted to relate degradation to consumption. They introduced the Ehrlich identity:

$$
\begin{aligned}
& I \equiv P A T, \text { where } \\
& \mathrm{I}=\text { Environmental Impact } \\
& \mathrm{P}=\text { Population } \\
& \mathrm{A}=\text { Affluence } \\
& \mathrm{T}=\text { Technology }
\end{aligned}
$$

Ekins and Jacobs (1995) and Dietz and Rosa (1994) have rephrased this identity as

$$
\begin{aligned}
& I \equiv P C T \text {, where: } \\
& \qquad \mathrm{C}=\text { Consumption }
\end{aligned}
$$

Other authors (Amalric, 1995; Ekins and Jacobs, 1995; Raskin, 1995) have used the composition of consumption. On the whole the IPAT approach provides the basic reference point for

\footnotetext{
${ }^{7}$ The early discussion is based on Rothman (1998).
} 
consumption based approaches. The broader question that is being asked is whether environmental degradation is anthropogenic or natural.

Production based approaches emphasize scale, composition and technique of production (Grossman \& Krueger, 1992; Panayotou, 1993). The scale of production is responsible for reducing the per unit energy use. As the composition of national income moves from agriculture to industry and then to services, an inverted u-shaped pattern in terms of the corresponding pollution levels is expected to emerge. Along with economic development better techniques of production and hence lower pollution per unit would result.

There are reasons to believe that the analysis of environmental degradation in terms of consumption based approaches can be seen as being analogous to production based approaches. The scale of production is related to the size of the market and hence to population. As the composition of the national income shifts from agriculture, that is subsistence-based, up to services there could be an initial rise in consumption levels due to 'pent-up' demand and a subsequent fall. The parallel between technique and technology is straightforward. Hence, the parallels to scale, composition and techniques can be seen as population, consumption and technology, which are the broad planks of the IPAT framework.

Although there is a parallel between the two approaches certain problems exist in relation to production-based approaches. The most fundamental of them is that demand for production activity is derived demand ${ }^{8}$ (Rees, 1995; Daly, 1996; Duchin, 1998). Further, Ekins (1977) argues that,

if the shift in production patterns has not been accompanied by a shift in consumption patterns two conclusions follow: (1) environmental effects due to the composition effect are being displaced from one country to the other rather than reduced; and (2) this means of reducing environmental impacts will not be available to the latest developing countries, because there will be no coming-up-behind them to which environmentally intensive activities can be located.

\footnotetext{
${ }^{8}$ If Say’s law does not hold good.
} 
Furthermore, production-based approaches do not capture the degradation that is caused directly by consumption, in terms of production and disposal of waste, vehicular pollution, excessive drawal of water resources, final consumption of energy and paper, etc. Another problem relates to taking income (as a proxy for production). While consumption may be a derivative of income, and may be closely related to it, there is reason to believe that consumption may nonetheless be a better measure than income in relation to the impact on environmental degradation. For instance, the problem at hand may be the measurement of pollution intensity across countries. The chosen measures could be either:

$\mathrm{I}_{\mathrm{pi}}=\frac{E_{i}}{N I_{i}}$ or $\mathrm{X}_{\mathrm{i}}=\frac{E_{i}}{C_{i}}$

where,

$$
\begin{aligned}
& \mathrm{Xi}=\text { Consumption pollution intensity in the } \mathrm{i} \text { th country } \\
& \mathrm{Ci}=\text { Consumption level of } \mathrm{i} \text { th country } \\
& \text { and } \mathrm{I}_{\mathrm{pi}} \text { is the Income-pollution intensity in the } \mathrm{i} \text { th country with } \\
& \mathrm{E}_{\mathrm{i}}=\text { Emissions of the } \mathrm{i} \text { th country } \\
& \mathrm{NI}_{\mathrm{i}}=\text { National Income of th } \mathrm{i} \text { the country }
\end{aligned}
$$

Now, if the propensity of consumption in the $\mathrm{j}$ th country is half that of the $i$ th country and if consumption level replaces NI in the denominator then

$$
\frac{X_{j}}{X_{i}}=2
$$

whereas

$$
\frac{I_{p i}}{I_{p j}}=1
$$


This illustrates the point that income based measures may tend to unduly narrow differentials where they exist.

While studying consumption some of the extant studies have termed waste as a problem of 'non-consumption’ (Hawken, 1995; Rees, 1990). However, there is a measurement problem if such an approach is taken to its logical conclusion. For instance, if energy intensity is being measured one may write

$$
\mathrm{C}=\mathrm{C}_{\mathrm{a}}+\mathrm{C}_{\mathrm{w}}
$$

where,

$$
\begin{aligned}
& \mathrm{C}_{\mathrm{a}}=\text { Actual consumption } \\
& \mathrm{C}_{\mathrm{w}}=\text { Waste during consumption }
\end{aligned}
$$

and

$$
\begin{aligned}
& \mathrm{N}_{\mathrm{p}}=\frac{V}{N I} \\
& \mathrm{~N}_{\mathrm{c}}=\frac{V}{C} \\
& \mathrm{~N}_{\mathrm{a}}=\frac{V}{C_{a}} \\
& \mathrm{~V}=\text { Energy use } \\
& \mathrm{N}_{\mathrm{p}}=\text { Production based measure of energy intensity } \\
& \mathrm{N}_{\mathrm{c}}=\text { Total consumption based measure of energy intensity } \\
& \mathrm{N}_{\mathrm{a}}=\text { Actual consumption based measure of energy intensity }
\end{aligned}
$$

The relationship between the three measures is

$$
\mathrm{N}_{\mathrm{p}}<\mathrm{N}_{\mathrm{c}}<\mathrm{N}_{\mathrm{a}}
$$

This would obviously create problems when measuring the performance across countries since the level of both consumption as well as waste would differ. Further, both these dimension cannot be mechanically subsumed within production. 
In the context of international trade Diwan and Shofik (1992) and Pearce and Warfood (1993) have emphasized that the North can improve local environmental quality at the cost of global pollution due to the 'debunking' technologies that they possess (Pollution Haven Hypothesis). To this must be added the fact that if consumption and disposal patterns were taken into account, the global pollution inequalities would get accentuated because in the north high levels of consumption (C) can continue at the cost of Cw being transferred to the South. Therefore, a consumption-based approach to the EKC whose interest is in knowing the levels of global environmental degradation and, more importantly, the distribution of degradation across the globe should be preferred.

Two recent consumption-based studies are Rothman (1998) and Suri and Chapman (1998). The former provides a useful review and meticulously charts the relationship between consumption and GDP and establishes an inverted U (EKC type) pattern in the case of certain commodities but does not go beyond that. It must be pointed out here that EKC does not imply that the consumption pattern has an inverted $U$ shape - only that environmental degradation has an inverted U shape when plotted against PCI. The contribution of Rothman lies in raising the question, "Is it possible to go further to more explicitly and completely link a measure of environmental impact to consumption?” (Rothman, 1998). On the other hand, Suri and Chapman (1998) have concentrated on 'energy consumption itself, as a chief source of a number of environmental problems'. Their model begins by estimating pollution as:

$$
P_{i j}=a_{i j} E_{i}
$$

where,

$$
\begin{aligned}
& \mathrm{a}_{\mathrm{ij}}=\text { Emission/unit-energy (emission co-efficient) } \\
& \mathrm{E}_{\mathrm{i}}=\text { Energy consumption } \\
& \mathrm{P}_{\mathrm{ij}}=\text { Pollutant } j \text { from energy source } i .
\end{aligned}
$$

Subsequently they substitute pollution intensity with energy intensity. (Since high energy intensity also generally implies high pollution intensity, the two terms are used interchangeably). Their final model uses GDP:

$$
\log \mathrm{E}_{\mathrm{i}} / \text { per capita }=\mathrm{f}\left(\mathrm{GDP},(\mathrm{GDP})^{2}\right)
$$


Hence they neither directly measure pollution (let alone environmental degradation, which is a broader concept) nor do they introduce consumption per se as an explanatory variable. Their subsequent models only include manufacturing and trade-related variables as explanatory variables. But nothing is done to modify the dependent variable - energy consumption. Effectively, then, there is no study that estimates the behaviour of environmental degradation against consumption.

\section{Methodology and Data}

Our modus operandi for arriving at a better understanding of the links between environmental degradation and consumption is as follows. Along the lines of Jha and Murthy (2003) we use the method of Principal Components Analysis (PCA) to construct an Environmental Degradation Index (EDI) for each country. We then identify outliers and influential observations among both the environmental and consumption related variables. Canonical Discriminant analysis is then used to classify development classes along environmental lines. We then estimate a simultaneous equation model to model the pattern of causation between PCI, consumption and environmental degradation. Finally we present an alternative consumption-based Human Development Index to UNDP's incomebased HDI. We then compare the ranking of countries according to the consumption-based HDI ranks with their ranking according to their EDI.

Two sets of data drawn from the Human Development Report (HDR) (UNDP (2000)) ${ }^{9}$ are used in the analysis. One relates to the environment and the other to developmental variables. For the formation of a composite index that would enable the estimation of a GEKC for 174 countries, we used cross-sectional data used in the HDR. The HDR contains data on the following environmental variables.

a. Internal renewable water resources per capita (cubic meters/ year);

b. Annual fresh water withdrawals per capita (hundred cubic meters);

c. Annual fresh water withdrawals as a percentage of water resources;

d. Average annual rate of deforestation (per cent);

e. Printing and writing paper consumed per 1000 persons;

\footnotetext{
${ }^{9}$ The subsequent volumes did not contain specific variables that were of interest to us
} 
f. Total CO2 emission (million metric tons);

g. Share of world total CO2 (per cent);

h. Per capita CO2 emissions (metric ton);

i. SO2 emissions per capita (kilograms).

\section{Environmental Degradation Index}

Data on SO2 was scanty so it was dropped. Internal renewable water resources per capita are very large in comparison to the other variables. Hence this variable is dropped. For a similar reason the variable "total CO2 emissions” was also dropped. Thus, we are left with six variables. ${ }^{10}$ These are:

1 PCFWW - Annual per capita fresh water withdrawals.

2. CENTFWW - Annual fresh water withdrawals as a percentage of water resources.

3. PAPCPM — Printing and writing paper consumed per capita.

4. PCCO2 - Per capita CO2 emission.

5. $\mathrm{CO} 2 \mathrm{SH}$ - Share of world total $\mathrm{CO} 2$.

6. DEFOR - Rate of deforestation.

Surely, there are additional indicators of GED such as bio-diversity, waste and soil degradation but paucity of comparable data prohibits us from using these variables. The selected variables were expressed as ratios or as per capita measures, in order to minimize scale problems. In certain cases, DEFOR was negative implying reforestation, for this reason and other reasons DEFOR was dropped. Data gaps (there were very few) were filled with help of substitute means based on values for neighboring countries. ${ }^{11}$

The 174 countries covered by the HDR have been classified into three classes according to the following criteria:

a. Human Development Index $\geq 0.8$ - High Human Development. This included Countries with HDI rank from 1 to 45 .

\footnotetext{
${ }^{10}$ Lewis-Beck (1994) (an authority on Factor Analysis) argues that care must be taken about the scale and code of variables

${ }^{11}$ SPSS package was used for estimation. It provides for substitute means being used for missing values. Neighboring data points were used for generating these substitute means. In any case, there were very few missing data points.
} 
b. Human Development Index 0.5 to 0.799 - Medium Human Development. This included countries with HDI rank from 46 to 139.

a. Human Development Index < 0.5 -Low Human Development which include countries with HDI rank (HDIR) from 140 to 174.

The HDR 2000 contains certain developmental variables related to consumption. We use the following to understand the underlying developmental causal factors.

1. Per Capita Consumption (CONS).

2. GDP per capita in PPP \$ (GDPPC\$).

3. Energy consumption per capita (ENERGY).

4. Value of international trade (exports plus imports) (TRADEV).

5. Rate of urbanization (URBAN)

If the objective is a simple summary of the information contained in the raw data, the use of component scores is desirable. It is possible to represent the components exactly from the combination of raw variables. The scores are obtained by combining the raw variables with weights that are proportional to their component loadings. In our case the component scores have been used for determining the weight of each of the raw variables in constructing a composite EDI for the ith country and, similarly, for other countries. As more and more components are extracted, the measure of the explanatory power would increase. However, this would defeat the purpose of reducing the dimensionality. It is necessary to strike a balance between parsimony and explanatory power.

Both the unrotated and rotated solutions explain exactly the same amount of variation in the variables. The choice between them hinges upon the interpretative power of each solution. Once the number of retained principal components is determined and the rotated component scores obtained, we have the choice of using the principal components as such or selecting a subset of variables from the larger set of variables. 
We were able to narrow down the number of variables from six to four. ${ }^{12}$ However, the principal components were themselves not directly used. We discard two variables, viz., the second (CENTFWW) and the sixth (DEFOR)) and define the EDI for the ith country as:

$$
\begin{aligned}
& E D I_{i}=\sum_{j=1}^{5} w_{j} \cdot x_{j i} \\
& \text { where; } \\
& \mathrm{w}_{\mathrm{j}}=\mathrm{j} \text { th component score, } \\
& \mathrm{x}_{\mathrm{ji}}=\text { value of the } \mathrm{j} \text { th variable for the } \mathrm{i} \text { th country; and } \mathrm{j}=1,3,4 \text { and } 5 . \\
& \text { GED is given by: }
\end{aligned}
$$

$$
G E D=\sum_{i=1}^{174} E D I_{i}
$$

\section{Identifying outliers and influential observations}

Principal Component Analysis allows identification of outlying observations. This is done by plotting the first two components, that are the most significant and observing which countries are beyond reasonable limits. An outlier could be so in a relative sense, if it significantly differs from the norm, in comparison with its neighbors. Three figures have been drawn for observing this - one each for the three development classes. But here a distinguishing feature is that while all influential observations are outliers, all outliers are not influential observations. The difference lies in the fact that influential observations have a significant impact on the component scores. The methodology involves the elimination of each suspect observation and re-estimation of the component scores. If the ratio of the original score to the new score remains the same then the particular country is not an influential observation. Especially, if the sign changes and the ratio is different from unity the particular country is to be treated as an influential observation, i.e., its absence leads to radical changes in the overall component scores.

\footnotetext{
${ }^{12}$ This discussion is postponed until the exercise of Discriminant Analysis is done.
} 


\section{Canonical Discriminant Analysis}

There could be various viewpoints about the causal links of GED. We consider three of these.

1. Human development that is broad-based and includes economic as well as social factors.

2. Consumption that is molded by economic and cultural factors that adjunct to economic factors.

3. Geo-physical factors that can be gauged by the common agro-climatic regions.

We classified the set of 174 countries, on which data are available in HDR 2000, into three classes by Canonical Discriminant Analysis, according to the criteria laid down in HDR i.e., on the basis of the level of the HD index. The null hypothesis is that environmentally degrading countries can be classified upon the basis of consumption-related causes. The alternative is that the classification should be according to geophysical causes and not consumption related factors. Thus, two exercises were done: (i) to classify the same set of countries on the basis of environmental degradation variable according to HDI and (ii) to classify them by consumption related variables according to HDI. If the null hypothesis were correct, the classification by environmental variables and that by consumption related variables would coincide. On the other hand if geophysical causes were behind degradation then the classification would have to be on a geographical basis.

\section{Simultaneous Equations Model}

Since causal factors are so enmeshed it is necessary to establish a causative framework, so as to separate the influence of the individual factors. To accomplish this we construct a simultaneous equations model. Our purpose is three-fold.

1. To explain the income generating factors (that are partly cultural).

2. To estimate a global consumption function based on income.

3. To predicted the GEKC with the help of consumption

We thus have the following three-equation framework.

$$
\begin{aligned}
& \text { GDPPC }=\mathrm{a}_{0}+\mathrm{a}_{1} * \text { ENERGY }+\mathrm{a}_{2} \text { TRADEV }+\mathrm{a}_{3} * \text { URBAN }+\mathrm{U}_{1} \\
& \text { CONSUMPTION }=\mathrm{b}_{0}+\mathrm{b}_{1} * \text { GDPPC }+\mathrm{U} 2 \\
& \text { EDI } \left.=\mathrm{c}_{0}+\mathrm{c}_{1} * \text { HDIR }\right)+\mathrm{c}_{1}(\text { HDIR })^{*^{2}}+\mathrm{c}_{1} \text { HDIR }^{*}
\end{aligned}
$$

We used 2SLS to estimate this set of equations. 


\section{Creation of the consumption-based HDI}

Our alternative consumption-based Human Development Index is based on three indicators:

1. Life expectancy at birth;

2. Educational attainment ${ }^{13}$;

3. Standard of living measured by real GDPPC in PPP \$.

Each variable has a minimum and maximum range.

1. Life expectancy: 25 to 85

2. Educational attainment: $0 \%$ to $100 \%$

3. Standard of living: (PPP\$) 100 to 40000

The general formula for computing each component is:

$$
\operatorname{Index}\left(X_{i}\right)=\frac{\text { Actual }_{i} \text { value }-\min \text { imum }_{i} \text { value }}{\text { Maximum }_{i} \text { value }-\min \text { imum }_{i} \text { value }}
$$

Income is taken to be a proxy for living standard. However, unlimited income may not be necessary to achieving a respectable level of human development. Therefore, over the years a complex formula was used for discounting income above a threshold level. Apart from the question of what that level should be, the problem with this procedure was that it discounted higher incomes excessively, as indicated by Anand and Sen (1999). Thereafter, they advocate more moderate discounting as in:

$$
W(y)=\frac{\log y-\log y_{\min }}{\log y_{\max }-\log y_{\min }}
$$

The justification for this is that this formula does not need a threshold nor does it penalize middleincome countries unduly.

The approach involving discounting clearly has a normative intent since it scales extreme high values. An implication is that even if developing countries so not attain such high values of income they will still benefit and, according to this calculus, the gap between their realized income and the high incomes of the developed countries would be narrower than would have been the case if such discounting had been eschewed. However, if no discounting is used the HDI would reflect how

\footnotetext{
${ }^{13}$ With two-third weightage for primary education.
} 
things stand, which is a positive approach. As a consequence of following this approach the actual gaps between the levels of income in developed countries and those attainable by developing countries would be revealed. Thus this approach would reveal the true inequalities of income. Once such inequalities are revealed their consequence for environmental degradation would also become relevant.

A measure of the inequalities in consumption related variables and environmental degradation variables can be gauged from Tables 1 to 3 . While the proportions may differ the parallelism is striking.

\section{Tables 1-3 here}

Table 1 is based on of the mean values of the respective developmental and environmental variables in proportion (Low: Medium: High) to HDI classes. Thus the construction of the HDI as it stands conceals more than it reveals.

We propose a consumption based HDI which can ultimately be used for estimating a GEKC based on a new measure of HDI. The methodology used is as follows. The existing HDI has been deflated to the extent of the component of income resulting in a net value. Per Capita real consumption has been derived from real GDP in PPP\$ and added back to the net value. It has then been averaged using equal weights as is done with the original index. Countries in various developmental classes have then been ranked according to the new Consumption based HDI.

\section{Results}

The distributions over the first two components of environmental variables are given in Figures 1 -3. While there may be some others that are outliers we have chosen the following (with reasons appended).

\section{Figures 1-3 here}


1. USA — outlier and large developed market economy.

2. Russia — vast country, an outlier and a non-market, declining economy.

3. China — outlier, vast, populous and non-market developing economy.

4. Finland — outlier (though) small and developed market economy.

5. Japan — small market economy, developed and populous and an outlier.

6. India — large, populous, mixed developing economy, not a significant outlier.

The component scores were worked out after eliminating each of these countries. The results are not reported for want of space. However, the broad conclusion is that the old to new scores remain within $10 \%$ of each other in all other cases. The only exception is that of USA. In the case of the USA the deviation is around $40 \%$ on an average across all environmental variables. In fact the sign on certain variables also changes and in the case of certain individual variables the change is nearly $100 \%$. Therefore, only USA is an influential observation. In fact, it is very influential. While some other countries are outliers they are not influential. Another significant result is that in both cases environmental and consumption related variable - the low developmental class has virtually not got any outlier. Their contribution to the environmental degradation is uniformly low. Finally, There is a striking similarity between the two lists of outliers. With some exceptions it can be said the outliers are the same (Figures 4-6). This provides a preliminary basis for believing that primarily it is consumption that is the 'cause' environmental degradation.

\section{Figures 4-6 here}

In the discriminant analysis we used the Box's M test for testing for the equality of population co-variance matrices. It revealed that they were not equal. F-tests with levels of significance between 5 and 10 per cent were used to include or exclude variables. On this basis we retained variables $1,3,4$ and 5 amongst environmental variables. The eigenvalues justified extraction of two linear discriminant functions. The prior probabilities were taken to be equal since there was no other 
information. These results hold good for both classifications. ${ }^{14}$ Finally, both classifications proved that the basis environmental degradation was not geophysical. In the case of environmental variables the classification was 70.1 per cent true. In the other case of classification it was beyond 81 per cent. The countries that have been classified together have little in common in geophysical terms. Hence, it can clearly be stated that human development, consumption and environmental degradation are all positively related. The country groupings are the same for all the three. Thus, urbanized, open, high income and high-energy use economies are clearly associated with a high degree of environmental degradation. Detailed results appear in Tables 4 to 8.

\section{Tables 4 to 8 here}

If the above premise is admitted, it takes us on to the question of the structure of causality. How does this causality work out? There are three stages to analyzing this. First, an economy with high energy use that is open to international trade and urbanized, has the potential to generate high incomes (See equation (4) and Table 9). All coefficients are significant and R bar sq. is 0.87 .

\section{Income generation function:}

$$
\text { GDPPC }=9569+0.57 * \text { ENERGY }+5.37 * \text { TRADEV }+42.24 * \text { URBAN }+\mathrm{U}_{1}
$$

(Intercept for Medium HDI class: 926 and Low HDI class: (-) 199)

All equations have been tested for other functional forms. Also slope and intercept dummies have been tried out in equations 4 and 5. Only the first equation shows significant intercept dummies. Low development countries have a negative intercept such that their income generating potential is low in absolute terms. Second, we also estimated the global consumption function:

\section{Global consumption function:}

CONSUMPTION $=315.52^{\mathrm{a}}+0.725 *$ GDPPC $+\mathrm{U} 2$

( ${ }^{a}$ not significant)

\footnotetext{
${ }^{14}$ Such results have not been reported. Interested readers can have the results from the authors.
} 
The estimated equation reveals that high income leads to high consumption (see Table 10). (All coefficients are significant and $\mathrm{R}$ bar sq. is 0.853.) The estimated global consumption function reveals that (i) it is in accordance with the long-term consumption function (the real consumption function) that does not have an intercept, and (ii) it is possible that even low-income countries have imbibed the consumption patterns of rich countries. This could be on account of openness, globalization and modernization. All this reflect a certain 'type of development'.

Finally, predicted consumption enters in the form of a new consumption based HDI and affects environmental degradation. It is captured in the last equation. (See Table 11) (All coefficients are significant and R bar sq. is 0.77). This is the Consumption-based global environmental Kuznets curve (GEKC).

\section{Consumption based Global Environmental Kuznets Curve:}

$\mathrm{EDI}=73.21-2.15 *(\mathrm{HDIR})+0.02 *(\mathrm{HDIR})^{*^{2}}-6.05 * \mathrm{HDIR}^{*^{3}}$

The cubic equation shows that the global EKC is dominated by high development countries. The low and medium countries hardly contribute to environmental degradation. The GEKC is certainly done not have an inverted U shape. Most importantly, the structure of causality is clear. A certain type of development leads to high incomes and consequent high consumption. This results in environmental degradation. The cause of entropy is high consumption. Unsustainable levels of consumption have been reached amongst high development countries. The GEKC is plotted in Figure 7.

\section{Figure 7 here.}

A cubic representation for the GEKC appears to be the most appropriate with highconsumption countries contributing excessively to GED and middle-consumption countries slightly less. Low-consumption countries are contributing insignificantly, or even negatively, to GED. This is broadly in agreement with the results on the income-based GEKC reported in Jha and Murthy (2003). 
Our final formal analysis consists of comparing consumption based HDI ranks with EDI ranks. If a country has a larger HDI number it indicates a lower ran and, hence, lower potential for degradation. If it has a larger EDI number it has lower potential for degradation. Therefore, a low EDI rank coupled with high HDI rank is desirable. This implies that negative correlation is desirable between HDIR and EDIR. The formula difference in ranks for comparison is EDIR - HDIR $>0$ is desirable. If we observe the developmental classes the results are clear. The high development class has an average of around (-) 5.8 ( $\Sigma$ (EDIR - HDIR)/ no. of countries). The correlation is 0.713 and, hence, undesirable. Medium class countries have a negative average of (-) 4.2 and a correlation of 0.68 , which is slightly better, but still undesirable. The low development class has an average of $(+)$ 23 and a correlation of (-) 0.68. Thus, their performance is the best! Detailed results are reported in tables 12 to 14.

\section{Tables 12 to 14 here.}

\section{Conclusion}

The two main contributions of this paper are to build a consumption-based HDI and to estimate a Global EKC based on consumption. A simultaneous equations model explains the causal structure that is responsible for Global Environmental Degradation. Further, with Canonical Discriminant Analysis it has been shown that GED does not have geo-physical basis but an anthropogenic basis. As a part of the system of equations a Global Consumption Function has been estimated that displays interesting results. In net, the paper attempts to establish that a certain 'type of development' that characterizes high income countries is responsible for Global Environmental Degradation. 


\section{References}

Amalric, F. (1995) "Population growth and the environmental crisis: beyond the obvious”, in V. Bhaskar and G. Andrews (eds), The North, the South and the Environment: Ecological concerns and the global economy, United Nations University Press, Tokyo, pp. 85-101.

Anand, S. and A. Sen (1999) “Income Components in the HDI — Alternative Formulations”, Occasional Papers, UNDP, Human Development Report Office, New York.

Daly, H. (1996) “Consumption: Value added, physical transformation and welfare”, in R. Costanza, O. Segura and Martinez-Alier (eds), Getting Down to Earth: Practical Applications of Ecological Economics, Island Press, Washington D.C., pp. 49-59.

Dietz, T. and E.A. Rosa (1994) "Rethinking the environmental impacts of population, affluence and technology”, Human Ecological Review, v. 1, pp. 277-300.

Divan, I and N. Shafik (1992) "Investment technology and the global environment: Towards International agreement in a world of disparities”, in. P. Low (ed.), International Trade and the Environment, The World Bank, Washington D.C. pp. 263-87.

Duchin, F. (1998) Structural Economics: Measuring changes in technology, lifestyles and the environment, Island Press, Washington D.C.

Ekins, P. (1997) “The Kuznets Curve for the Environment and Economic Growth: Examining the Evidence”, Environment and Planning, 29, Oct.

Ekins, P. and M. Jacob (1995) "Environmental Sustainability and the Growth of GDP: conditions for compatibility”, in V. Bhaskar and G. Andrew (eds), The North, the South and the Environment: Ecological Constraints and the Global Economy, United Nations University Press, Tokyo, pp. 9-46.

Ehrlich, P.R. and J.P. Holdren (1971) “Impact of population growth” Science, v. 171, pp. 1212-17.

Grossman, G.M. (1995) “Pollution and Growth: What do we know?”, in I. Goldin and L.A.Winters (eds), The Economics of Sustainable Development, Cambridge University Press, New York, pp. 19-46.

Grossman, G.M. and A.B. Krueger (1992) Environmental Impacts of A North American Free Trade Agreement, Woodrow Wilson School, Princeton, New Jersey.

Grossman, G.M. and A.B. Krueger (1994) Economic Growth and the Environment. NBER Working Paper \#4634, National Bureau of Economic Research.

Hawken, P. (1995) Natural Capitalism: The next industrial revolution, National Round Table on the Environment and the Economy, Ottawa.

Jha, R. and K.V. Bhanu Murthy (2000) "Sustainability: Behavior, Property Rights and Economic Growth" Proceedings of the World Congress on Managing and Measuring Sustainable Development, Toronto, Canada.

Jha, R. and J. Whalley (2001) “The Environmental Regime in Developing Countries”, in Carlo Carraro and Gilbert E. Metcalf (eds), Behavioral and Distributional Effects of Environmental Policy, Chicago: University of Chicago Press for NBER.

Jha, R. and K.V. Bhanu Murthy (2003) “An inverse global environmental Kuznets curve”, Journal of Comparative Economics, v. 31, pp. 352-68.

Kuznets, S. (1955) “Economic Growth and Income Inequality”, American Economic Review, v. 49, pp. 1-28.

Lewis-Beck, M. (ed.) (1994) Factor Analysis and Related Techniques, New Delhi: Sage Toppan. 
Panayotou, T. (1993) "Demystifying the Environmental Kuznets Curve: Turning a Black Box into a Policy Tool”, Environment and Development Economics, vol. 2, pp. 465-84.

Pearce, D.W. and J.J. Warford (1993) World Without End: Economics, environment and sustainable development, Oxford University Press, New York.

Radetzki, M. (1992) “Economic growth and the environment”, in P. Low (ed), International Trade and Environment, The World Bank, Washington D.C. pp. 121-36.

Raskin, P.D. (1995) “Methods for estimating the population contribution to environmental change”, Ecological Economics, v. 15, pp. 225-33.

Rees, W.E. (1990) “The Ecology of Sustainable Development”, The Ecologist, v. 20(1), pp. 18-23.

Rees, W.E. (1995) "Reducing the ecological footprint of consumption”, The workshop on policy measures for changing consumption patterns, Seoul, www.earthsummit2002.org/roadmap/consumpt.htm .

Rothman, D. (1998) “Environmental Kuznets Curve: Real Progress or Passing the buck? A Case for Consumption Based Approaches”, Ecological Economics, v. 25, pp. 177-94.

Sagar, A. and A. Najam (1998) “Human Development Index: a critical review”, Ecological Economics, v. 25, pp. 249-64.

Suri, V. and D. Chapman (1998). "Economic Growth Trade and Energy: Implications for the Environmental Kuznets Curve”, Ecological Economics, v. 25, pp. 147-60.

United Nations (2000) Human Development Report, UNDP, New York. 
FIGURE 1

HIGH DEVELOPMENT OUTLIERS

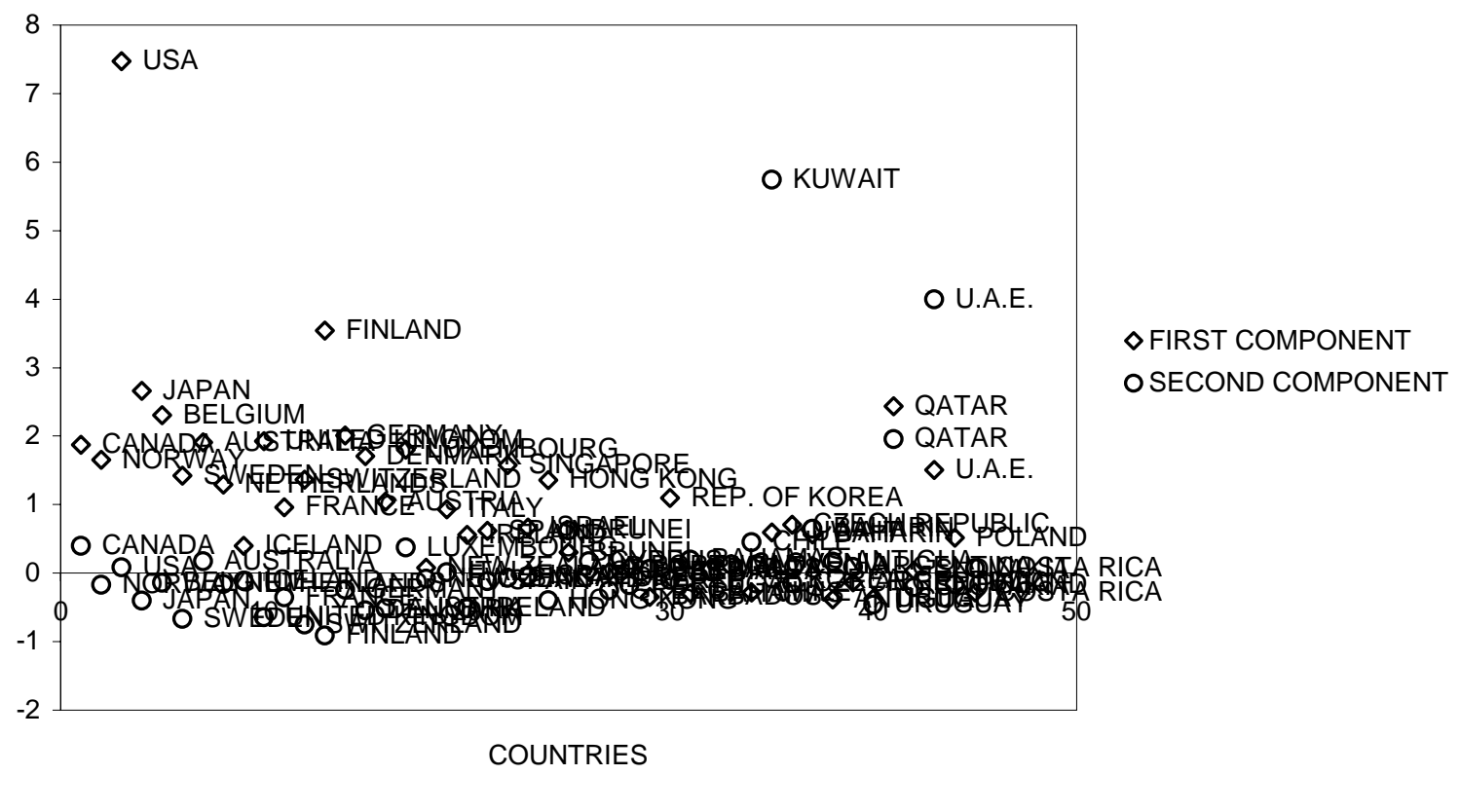

FIGURE 2

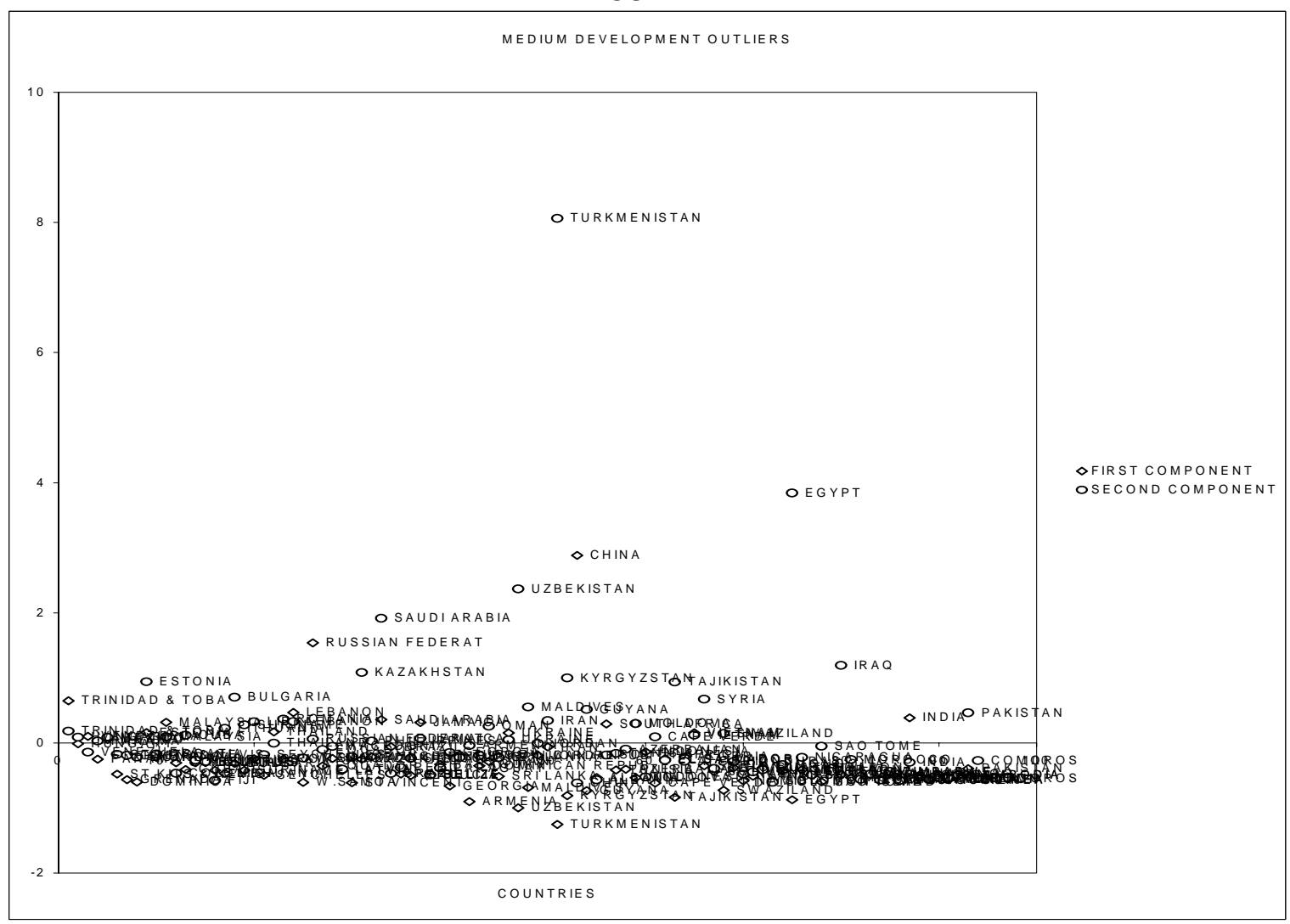


FIGURE 3

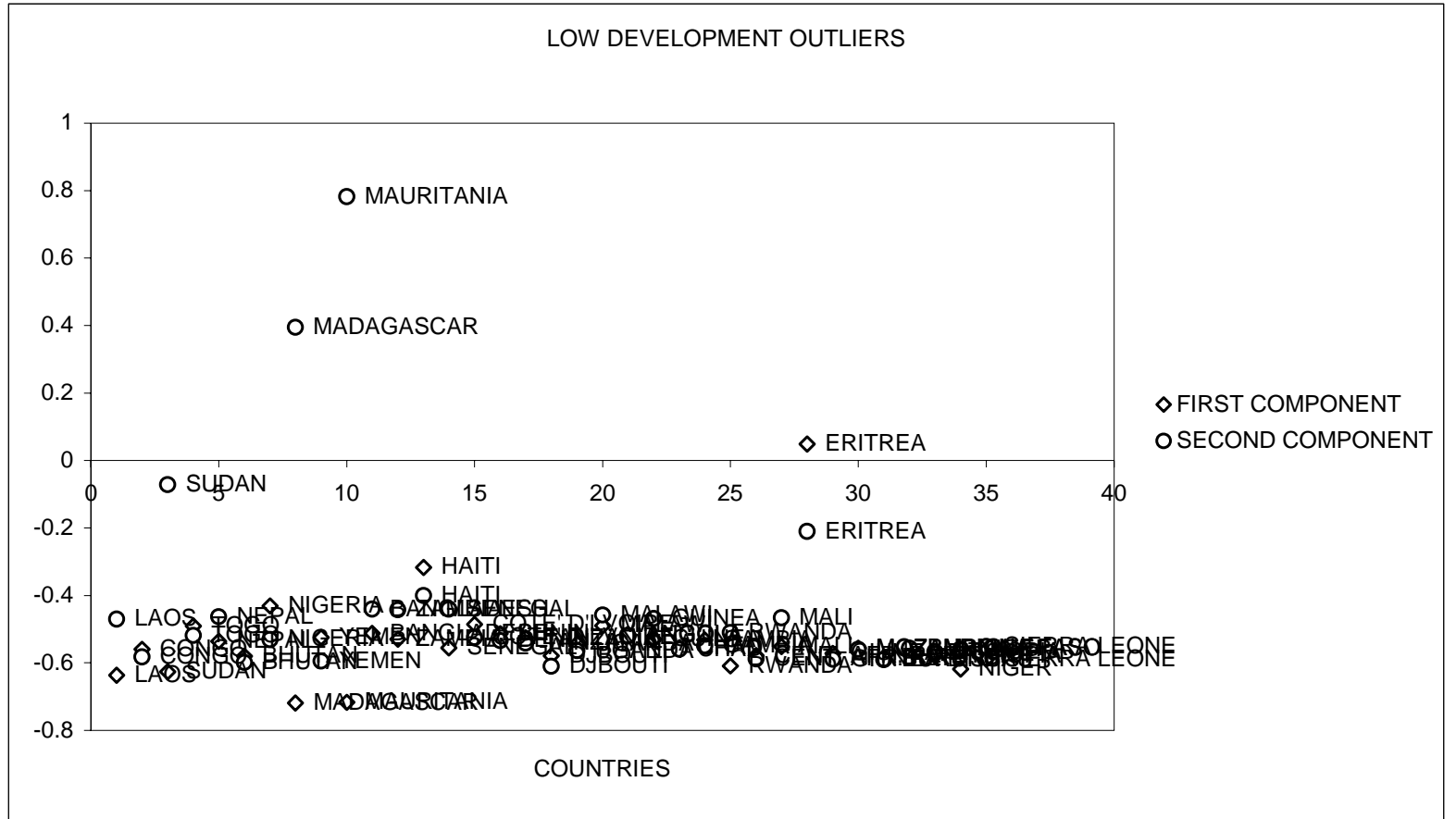

Figure - 4

High Development Countries - Consumption Outliers

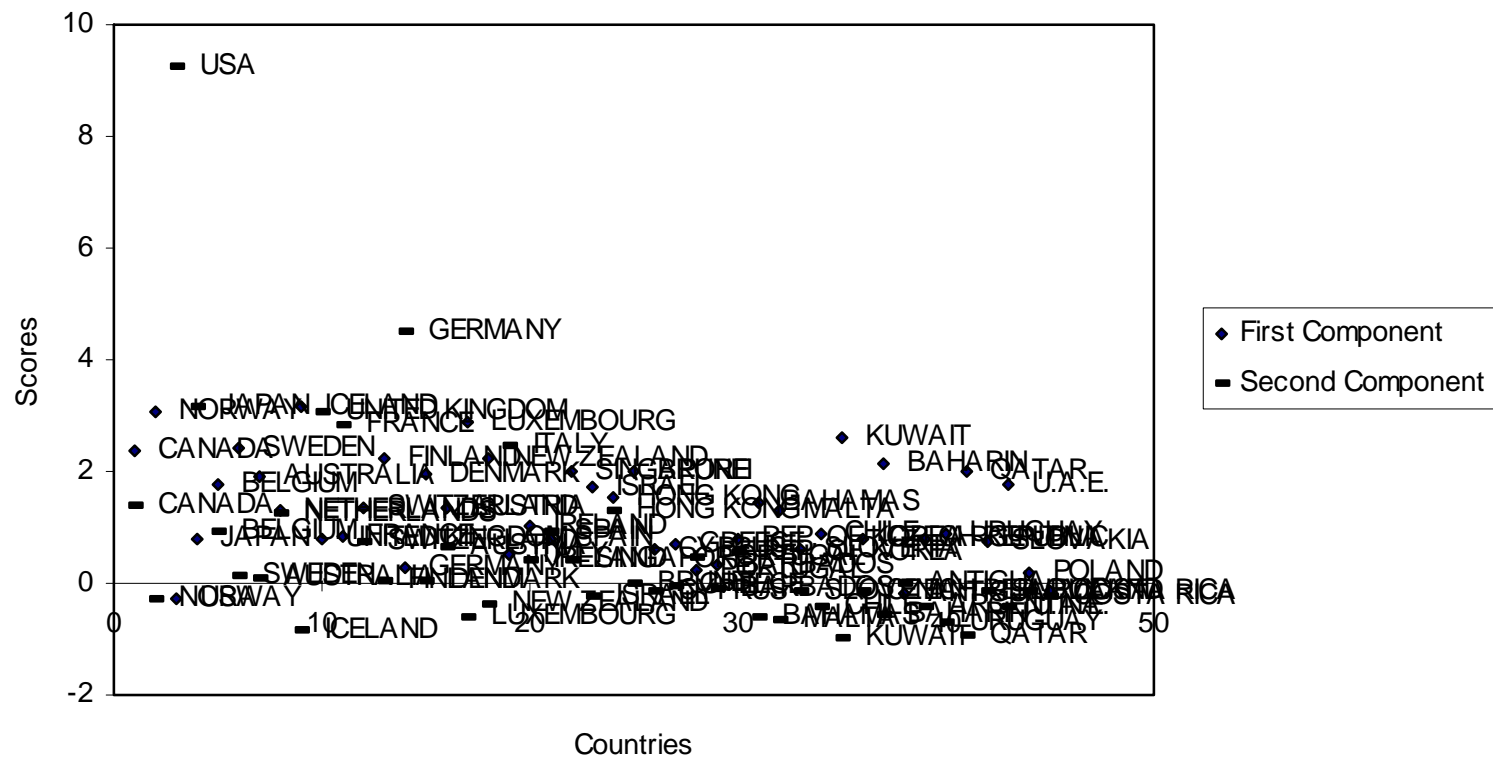


Figure - 5

Medium Development Countries - Consumption Outliers

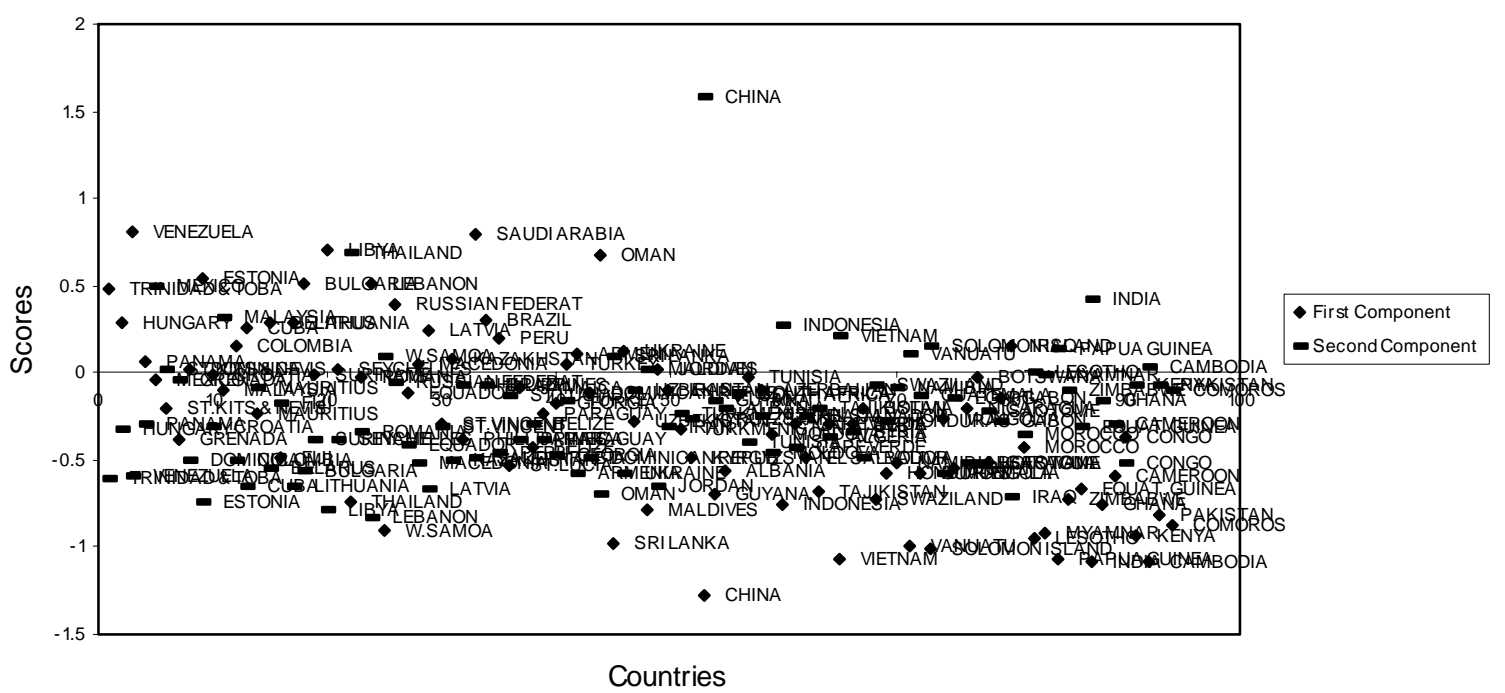

Figure - 6

Low Development Countries - Consumption Outliers

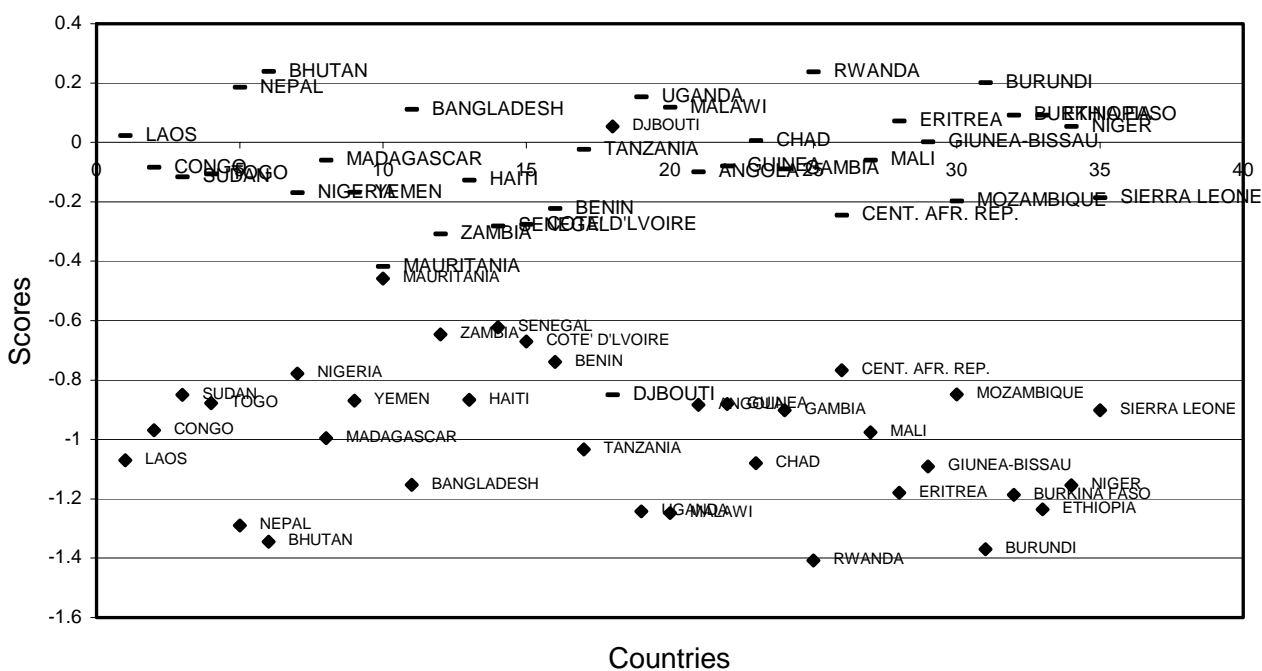


FIGURE 7

GLOBAL CONSUMPTION BASED GEKC

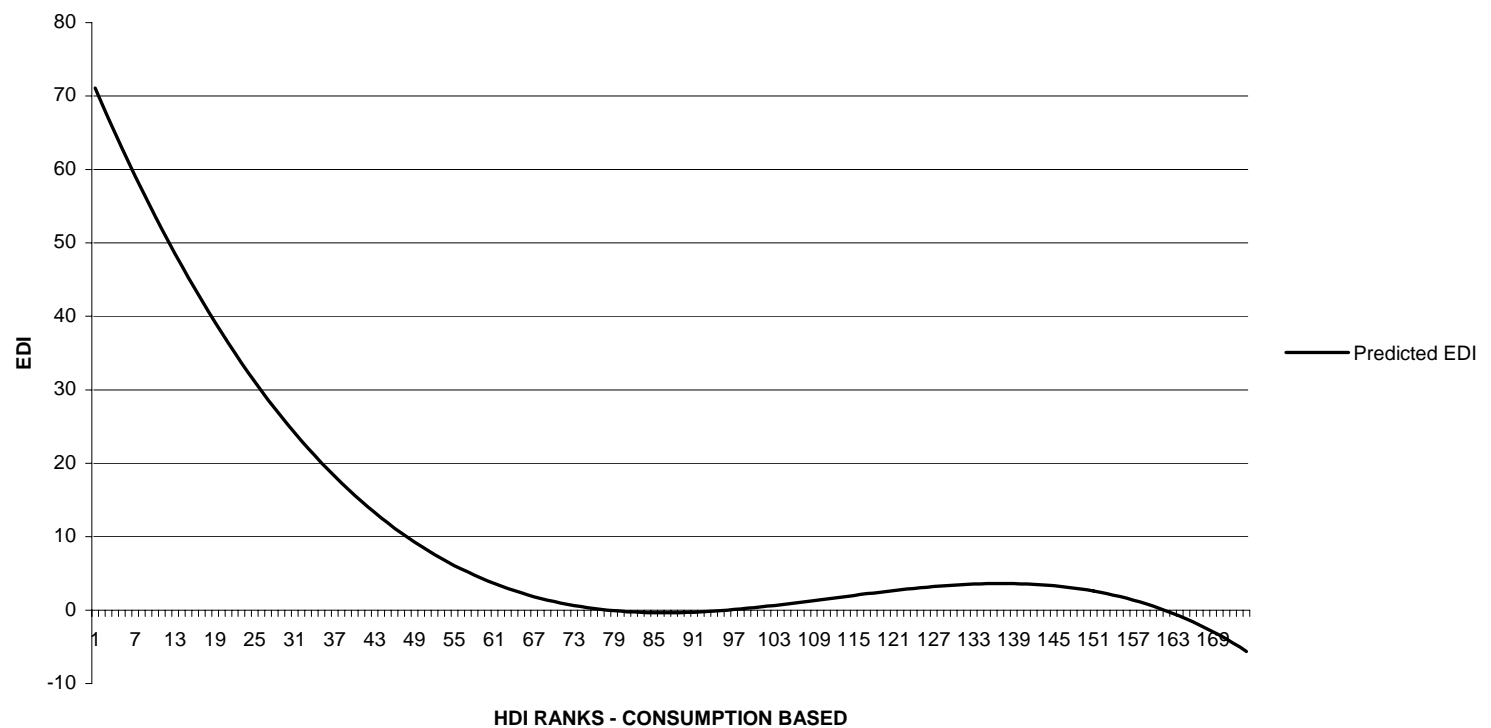

Table 1

\begin{tabular}{|c|c|c|c|}
\hline $\begin{array}{c}\text { DEVELOPMENTAL } \\
\text { STATUS }\end{array}$ & LOW:MIDDLE:HIGH & ENVIRONMENTAL & LOW:MIDDLE:HIGH \\
\hline Consumption & $1: 3: 14$ & Water Consumption & $1: 5: 7$ \\
\hline GDP (per capita) & $1: 4: 18$ & Paper Consumption & $1: 21: 240$ \\
\hline Energy Consumption & $1: 15: 77$ & CO2 (per capita) & $1: 6: 23$ \\
\hline Trade & $1: 10: 200$ & CO2 Share & $1: 30: 60$ \\
\hline Urbanization & $1: 2: 3$ & & \\
\hline
\end{tabular}

Table 2

Basic Statistics - Environmental Degradation

\begin{tabular}{|c|c|c|c|c|c|c|}
\hline \multicolumn{7}{|c|}{ High HDI } \\
\hline & PCFWW & CENTFW & PAPCM & PCCO2 & $\mathrm{CO} 2 \mathrm{SHA}$ & DEFOR \\
\hline Mean & 7.2 & 107.9 & 59.66 & 11.09 & 1.09 & -0.1 \\
\hline S. Dev & 4.0 & 445.1 & 51.1 & 9.16 & 3.36 & 0.74 \\
\hline $\mathrm{CV}$ & 0.55 & 4.12 & 0.85 & 0.82 & 3.08 & -6.97 \\
\hline \multicolumn{7}{|c|}{ Medium HDI } \\
\hline Mean & 7.08 & 80.29 & 4.21 & 3.03 & 0.46 & 0.73 \\
\hline S. Dev & 8.93 & 315.3 & 5.57 & 3.24 & 1.65 & 1.51 \\
\hline $\mathrm{CV}$ & 1.26 & 3.92 & 1.32 & 1.07 & 3.58 & 2.05 \\
\hline \multicolumn{7}{|c|}{ Low HDI } \\
\hline Mean & 1.56 & 15.02 & 0.22 & 0.56 & 0.017 & 0.73 \\
\hline S. Dev & 3.09 & 68.8 & 0.38 & 1.87 & 0.05 & 0.64 \\
\hline CV & 1.97 & 4.58 & 1.69 & 3.35 & 3.31 & 0.87 \\
\hline
\end{tabular}


Table - 3

Basic Statistics - Consumption Patterns

\begin{tabular}{|c|c|c|c|c|c|c|c|c|}
\hline & CONS & & GDPPC\$ & & ENERGY & & TRADEV & URBAN \\
\hline \multicolumn{9}{|l|}{ High } \\
\hline Mean & 13801.29 & Mean & 18477 & Mean & 7735.67 & Mean & 231.396 & 76.207 \\
\hline Std. Dev. & 4616.399 & Std. Dev. & 6349.3 & Std. Dev. & 5249.08 & Std. Dev. & Std. Dev. & 16.508 \\
\hline C.V. & 0.33449 & & 0.3436 & & 0.67856 & & 1.65725 & 0.2166 \\
\hline \multicolumn{9}{|l|}{ Medium } \\
\hline Mean & 3299.79 & Mean & 4120.5 & Mean & 1494.79 & Mean & 26.4361 & 51.92 \\
\hline Std. Dev. & 1645.595 & Std. Dev. & 2245.2 & Std. Dev. & 1385.27 & Std. Dev. & 55.2395 Std. Dev. & 18.437 \\
\hline C.V. & 0.498697 & & 0.5449 & & 0.92674 & & 2.08955 & 0.3551 \\
\hline \multicolumn{9}{|l|}{ Low } \\
\hline Mean & 979.1671 & Mean & 1095 & Mean & 95 & Mean & 2.81571 Mean & 28.989 \\
\hline Std. Dev. & 325.2334 & Std. Dev. & 392.37 & Std. Dev. & 128.742 & Std. Dev. & 4.45418 Std. Dev. & 15.192 \\
\hline C.V. & 0.332153 & & 0.3583 & & 1.35518 & & 1.5819 & 0.5241 \\
\hline
\end{tabular}

Table 4

Component Score Coefficient Matrix of Environmental Variables

Component

$12 \quad 3 \quad 4$

\begin{tabular}{lllll} 
PCFWW & .301 & .392 & -.111 & .459 \\
CENTFW & .243 & .532 & .354 & -.131 \\
PAPCPM & .299 & -.451 & .066 & -.319 \\
PCCO2 & .383 & -.062 & .264 & -.506 \\
CO2SHA & .237 & -.362 & .301 & .791 \\
DEFOR & -.270 & .011 & .905 & .016 \\
\hline
\end{tabular}

Extraction Method: Principal Component Analysis.

\begin{tabular}{|cccc|}
\hline \multicolumn{5}{c}{ Classification Function Coefficients of Environmental Variables } \\
& CLASS & & \\
& 1 & 2 & 3 \\
PCFWW & .120 & .164 & $5.292 \mathrm{E}-02$ \\
PAPCPM & $8.845 \mathrm{E}-02$ & $7.363 \mathrm{E}-03$ & $5.964 \mathrm{E}-04$ \\
PCCO2 & .380 & $8.749 \mathrm{E}-02$ & $1.792 \mathrm{E}-02$ \\
DEFOR & .181 & .747 & .575 \\
(Constant) & -6.270 & -2.104 & -1.356 \\
\hline
\end{tabular}

Fisher's linear discriminant functions 
Table 6

Classification Results of Environmental Variables

Classification Results

\begin{tabular}{|c|c|c|c|c|c|c|}
\hline \multicolumn{7}{|c|}{$\begin{array}{l}\text { Predicted Group } \\
\text { Membership }\end{array}$} \\
\hline & & CLASS & 1 & 2 & 3 & \\
\hline \multirow[t]{6}{*}{ Original } & Count & 1 & 34 & 10 & 1 & 45 \\
\hline & & 2 & 2 & 57 & 35 & 94 \\
\hline & & 3 & 0 & 4 & 31 & 35 \\
\hline & $\%$ & 1 & 75.6 & 22.2 & 2.2 & 100.0 \\
\hline & & 2 & 2.1 & 60.6 & 37.2 & 100.0 \\
\hline & & 3 & .0 & 11.4 & 88.6 & 100.0 \\
\hline
\end{tabular}

a $70.1 \%$ of original grouped cases correctly classified.

Table 7

Classification Results of Developmental Variables

Predicted Group Membership

Total

\begin{tabular}{|c|c|c|c|c|c|c|}
\hline & & CLASS & 1 & 2 & 3 & \\
\hline \multirow[t]{6}{*}{ Original } & Count & 1 & 40 & 5 & 0 & 45 \\
\hline & & 2 & 0 & 69 & 25 & 94 \\
\hline & & 3 & 0 & 3 & 32 & 35 \\
\hline & $\%$ & 1 & 88.9 & 11.1 & .0 & 100.0 \\
\hline & & 2 & .0 & 73.4 & 26.6 & 100.0 \\
\hline & & 3 & .0 & 8.6 & 91.4 & 100. \\
\hline
\end{tabular}

a $81.0 \%$ of original grouped cases correctly classified.

Table 8

Classification Function Coefficients of Developmental Variables

Classification Function Coefficients

\section{CLASS}

1

2

3

cons

1.438E-03

3.540E-04

1.048E-04

gdppc

6.447E-04

$-9.956 \mathrm{E}-05$

$-1.352 \mathrm{E}-04$

tradev

$-7.931 \mathrm{E}-03$

urban

.160

(Constant)

$-22.148$

$-1.906 \mathrm{E}-03$

$-3.554 \mathrm{E}-04$

.169

.103

$-5.841$

$-2.570$

Fisher's linear discriminant functions 
Table 9

PREDICTED GDP PER CAPITA PPP \$

\begin{tabular}{|c|c|c|c|c|c|c|}
\hline \multicolumn{2}{|c|}{ Regression Statistics } & & & & & \\
\hline Multiple R & 0.9353 & & & & & \\
\hline R Square & 0.874786 & & & & & \\
\hline \multicolumn{7}{|l|}{ Adjusted R } \\
\hline Square & 0.87106 & & & & & \\
\hline Standard Error & 2752.602 & & & & & \\
\hline Observations & 174 & & & & & \\
\hline \multicolumn{7}{|l|}{ ANOVA } \\
\hline & $d f$ & SS & $M S$ & $F$ & Significance $F$ & \\
\hline Regression & 5 & $8.89 \mathrm{E}+09$ & $1.78 \mathrm{E}+09$ & 234.7414 & $7.75 E-74$ & \\
\hline Residual & 168 & 1.27E+09 & 7576816 & & & \\
\hline \multirow[t]{2}{*}{ Total } & 173 & $1.02 \mathrm{E}+10$ & & & & \\
\hline & Coefficients & Standard Error & $t$ Stat & $P$-value & Lower 95\% & Upper 95\% \\
\hline Intercept & 9569.035 & 1065.806 & 8.978215 & $5.38 \mathrm{E}-16$ & 7464.936 & 11673.13 \\
\hline ENERGY & 0.574461 & 0.07791 & 7.373341 & 7.23E-12 & 0.420651 & 0.72827 \\
\hline TRADEV & 5.377281 & 1.070506 & 5.023122 & 1.29E-06 & 3.263904 & 7.490658 \\
\hline URBAN & 42.24545 & 12.73208 & 3.318031 & 0.001111 & 17.10995 & 67.38094 \\
\hline DMHDI & -8642.79 & 714.0057 & -12.1046 & 1.19E-24 & -10052.4 & -7233.21 \\
\hline DLHDI & -9768.41 & 950.6086 & -10.276 & 1.59E-19 & -11645.1 & -7891.74 \\
\hline
\end{tabular}

Table 10

GLOBAL CONSUMPTION FUNCTION-

Regression Statistics

Multiple R

R Square

Adjusted R Square $\quad 0.853144393$

Standard Error 2153.682354

Observations 174

ANOVA

Regression

Residual

df

1

172

173

Coefficients

Intercept

315.5274658

PreGDPC

0.724375012

SS
4666307113
797795801.2
5464102914
Standard Error
232.1234466
0.02283802

MS

$4666307113 \quad 1006.027886$

$4638347.681 \quad$ Significance F

8.98378E-74

t Stat P-value

$1.359308895 \quad 0.175828244$

$31.71794265 \quad 8.98378 \mathrm{E}-74$

Table 11

\begin{tabular}{|c|c|c|c|c|}
\hline \multicolumn{5}{|c|}{ CONSUMPTION BASED GLOBAL EKC } \\
\hline Regression Statistic & & & & \\
\hline Multiple R & 0.878615244 & & & \\
\hline R Square & 0.771964746 & & & \\
\hline Adjusted R Square & 0.767940595 & & & \\
\hline Standard Error & 9.733421524 & & & \\
\hline Observations & 174 & & & \\
\hline \multicolumn{5}{|l|}{ ANOVA } \\
\hline & Df & SS & MS & $\mathrm{F}$ \\
\hline Regression & 3 & 54522.46217 & 18174.15406 & 191.8329218 \\
\hline Residual & 170 & 16105.71408 & 94.73949457 & Significance $\mathrm{F}$ \\
\hline \multirow[t]{2}{*}{ Total } & 173 & 70628.17625 & & $2.4762 E-54$ \\
\hline & Coefficients & Standard Error & t Stat & P-value \\
\hline Intercept & 73.20980166 & 3.016326333 & 24.27118076 & 4.01446E-57 \\
\hline HDIR_C & -2.154849616 & 0.148842285 & -14.47740218 & 1.81519E-31 \\
\hline HDIR_C2 & 0.020315142 & 0.001973325 & 10.29487898 & 1.26734E-19 \\
\hline HDIR_C3 & $-6.05419 E-05$ & 7.41349E-06 & -8.166457921 & $6.88054 \mathrm{E}-14$ \\
\hline
\end{tabular}


Table 12

High Development Countries - Consumption Based HDI Ranks

\begin{tabular}{|c|c|c|c|c|}
\hline COUNTRY & EVN1345 & HDIR_C & EDIR & DIFFR \\
\hline FINLAND & 129.1098 & 8 & 1 & -7 \\
\hline USA & 88.28163 & 1 & 2 & 1 \\
\hline BELGIUM & 87.45989 & 12 & 3 & -9 \\
\hline HONG KONG & 67.17299 & 21 & 4 & -17 \\
\hline JAPAN & 65.19045 & 7 & 5 & -2 \\
\hline DENMARK & 64.12561 & 18 & 6 & -12 \\
\hline SWEDEN & 62.24197 & 4 & 7 & 3 \\
\hline SWITZERLAND & 59.58641 & 17 & 8 & -9 \\
\hline UNITED KINGDOM & 59.06618 & 9 & 9 & 0 \\
\hline CANADA & 57.56984 & 2 & 10 & 8 \\
\hline LUXEMBOURG & 55.09849 & 14 & 11 & -3 \\
\hline NORWAY & 55.04546 & 3 & 12 & 9 \\
\hline AUSTRALIA & 53.97511 & 11 & 13 & 2 \\
\hline GERMANY & 50.0116 & 6 & 14 & 8 \\
\hline NETHERLANDS & 48.74706 & 13 & 15 & 2 \\
\hline AUSTRIA & 46.47768 & 20 & 16 & -4 \\
\hline SINGAPORE & 42.99178 & 22 & 17 & -5 \\
\hline FRANCE & 39.58055 & 10 & 18 & 8 \\
\hline REP. OF KOREA & 34.29894 & 25 & 19 & -6 \\
\hline ITALY & 33.47212 & 16 & 20 & 4 \\
\hline IRELAND & 32.64211 & 24 & 21 & -3 \\
\hline ISRAEL & 30.42819 & 23 & 22 & -1 \\
\hline SPAIN & 28.87577 & 19 & 23 & 4 \\
\hline ICELAND & 24.31512 & 5 & 24 & 19 \\
\hline U.A.E. & 23.44568 & 43 & 25 & -18 \\
\hline CZECH REPUBLIC & 22.85472 & 29 & 26 & -3 \\
\hline QATAR & 21.17899 & 40 & 27 & -13 \\
\hline PORTUGAL & 20.58546 & 41 & 28 & -13 \\
\hline MALTA & 20.07649 & 28 & 29 & 1 \\
\hline SLOVENIA & 17.52599 & 32 & 30 & -2 \\
\hline ESTONIA & 17.44084 & 47 & 31 & -16 \\
\hline KUWAIT & 17.30319 & 26 & 32 & 6 \\
\hline GREECE & 15.45741 & 27 & 33 & 6 \\
\hline MALAYSIA & 15.02806 & 77 & 34 & -43 \\
\hline POLAND & 14.13907 & 39 & 35 & -4 \\
\hline HUNGARY & 14.0592 & 51 & 36 & -15 \\
\hline CYPRUS & 13.69349 & 31 & 37 & 6 \\
\hline NEW ZEALAND & 13.40563 & 15 & 38 & 23 \\
\hline BAHARIN & 13.29049 & 30 & 39 & 9 \\
\hline SOUTH AFRICA & 11.93103 & 109 & 40 & -69 \\
\hline CHINA & 10.86087 & 92 & 41 & -51 \\
\hline TRINIDAD \& TOBA & 10.53466 & 49 & 42 & -7 \\
\hline SLOVAKIA & 10.40129 & 34 & 43 & 9 \\
\hline THAILAND & 9.68284 & 95 & 44 & -51 \\
\hline ARGENTINA & 9.40481 & 38 & 45 & 7 \\
\hline \multicolumn{4}{|c|}{ Mean Difference in EDI and HDI ranks } & -5.82857 \\
\hline \multicolumn{4}{|c|}{ Correlation between EDI and HDI ranks } & 0.712928 \\
\hline
\end{tabular}


Table 13

Medium Development Countries - Consumption Based HDI Ranks

\begin{tabular}{|c|c|c|c|c|}
\hline COUNTRY & EVN1345 & HDIR_C & EDIR & DIFFR \\
\hline RUSSIAN FEDERAT & 9.23079 & 50 & 46 & -4 \\
\hline CROATIA & 8.56382 & 56 & 47 & -9 \\
\hline CHILE & 8.44825 & 37 & 48 & 11 \\
\hline LEBANON & 8.33898 & 75 & 49 & -26 \\
\hline BRAZIL & 7.76332 & 87 & 50 & -37 \\
\hline VENEZUELA & 7.71494 & 55 & 51 & -4 \\
\hline BARBADOS & 7.38849 & 35 & 52 & 17 \\
\hline SAUDI ARABIA & 7.33001 & 89 & 53 & -36 \\
\hline BRUNEI & 6.85549 & 42 & 54 & 12 \\
\hline TURKEY & 6.84998 & 97 & 55 & -42 \\
\hline URUGUAY & 6.37797 & 36 & 56 & 20 \\
\hline MEXICO & 6.31405 & 60 & 57 & -3 \\
\hline MAURITIUS & 5.7542 & 98 & 58 & -40 \\
\hline JAMAICA & 5.27603 & 71 & 59 & -12 \\
\hline PANAMA & 4.82035 & 63 & 60 & -3 \\
\hline COLOMBIA & 4.81408 & 72 & 61 & -11 \\
\hline VIETNAM & 4.69372 & 104 & 62 & -42 \\
\hline INDONESIA & 4.62732 & 110 & 63 & -47 \\
\hline JORDAN & 4.60167 & 90 & 64 & -26 \\
\hline MACEDONIA & 4.45582 & 59 & 65 & 6 \\
\hline BAHAMAS & 4.42449 & 33 & 66 & 33 \\
\hline ERITREA & 4.368 & 168 & 67 & -101 \\
\hline $\mathrm{FIJI}$ & 4.25514 & 69 & 68 & -1 \\
\hline ROMANIA & 4.22913 & 65 & 69 & 4 \\
\hline LATVIA & 3.93037 & 64 & 70 & 6 \\
\hline ST.LUCIA & 3.86032 & 99 & 71 & -28 \\
\hline LITHUANIA & 3.83695 & 52 & 72 & 20 \\
\hline TUNISIA & 3.61142 & 108 & 73 & -35 \\
\hline BULGARIA & 3.51158 & 46 & 74 & 28 \\
\hline EL SALVADOR & 3.50248 & 106 & 75 & -31 \\
\hline UKRAINE & 3.3924 & 53 & 76 & 23 \\
\hline IRAN & 3.2621 & 103 & 77 & -26 \\
\hline COSTA RICA & 3.0706 & 44 & 78 & 34 \\
\hline INDIA & 3.04004 & 127 & 79 & -48 \\
\hline ANTIGUA & 2.95549 & 45 & 80 & 35 \\
\hline DOMINICAN REPUB & 2.85132 & 96 & 81 & -15 \\
\hline ALGERIA & 2.8436 & 114 & 82 & -32 \\
\hline PHILLIPPINES & 2.63412 & 73 & 83 & 10 \\
\hline KAZAKHSTAN & 2.56127 & 62 & 84 & 22 \\
\hline ST.KITS \& NEVIS & 2.50832 & 79 & 85 & 6 \\
\hline OMAN & 2.49502 & 101 & 86 & -15 \\
\hline PERU & 2.4135 & 80 & 87 & 7 \\
\hline LIBYA & 2.3716 & 70 & 88 & 18 \\
\hline BELARUS & 2.34848 & 57 & 89 & 32 \\
\hline ALBANIA & 2.33998 & 88 & 90 & 2 \\
\hline IRAQ & 2.18456 & 124 & 91 & -33 \\
\hline SEYCHELLES & 2.17032 & 94 & 92 & -2 \\
\hline
\end{tabular}




\begin{tabular}{|c|c|c|c|c|}
\hline SURINAME & 2.01364 & 68 & 93 & 25 \\
\hline GUATEMALA & 1.99063 & 123 & 94 & -29 \\
\hline EQUADOR & 1.89427 & 81 & 95 & 14 \\
\hline PARAGUAY & 1.84404 & 86 & 96 & 10 \\
\hline GABON & 1.4369 & 135 & 97 & -38 \\
\hline HONDURAS & 1.43298 & 113 & 98 & -15 \\
\hline EGYPT & 1.42257 & 120 & 99 & -21 \\
\hline AZERBAIJAN & 1.41965 & 67 & 100 & 33 \\
\hline SRI LANKA & 1.40251 & 91 & 101 & 10 \\
\hline MONGOLIA & 1.40007 & 107 & 102 & -5 \\
\hline MOROCCO & 1.2786 & 126 & 103 & -23 \\
\hline BOLIVIA & 1.27617 & 112 & 104 & -8 \\
\hline BELIZE & 1.26153 & 93 & 105 & 12 \\
\hline CUBA & 1.2514 & 48 & 106 & 58 \\
\hline MOLDOVA & 1.22651 & 78 & 107 & 29 \\
\hline MALDIVES & 1.201418 & 100 & 108 & 8 \\
\hline W.SAMOA & 0.96132 & 84 & 109 & 25 \\
\hline SYRIA & 0.94073 & 111 & 110 & -1 \\
\hline ZAMBIA & 0.92572 & 149 & 111 & -38 \\
\hline KENYA & 0.82479 & 134 & 112 & -22 \\
\hline CONGO & 0.7764 & 130 & 113 & -17 \\
\hline COTE' D'LVOIRE & 0.76089 & 158 & 114 & -44 \\
\hline ZIMBABWE & 0.66462 & 131 & 115 & -16 \\
\hline LESOTHO & 0.646675 & 125 & 116 & -9 \\
\hline BANGLADESH & 0.62339 & 150 & 117 & -33 \\
\hline GRENADA & 0.62332 & 66 & 118 & 52 \\
\hline DOMINICA & 0.55832 & 54 & 119 & 65 \\
\hline NIGERIA & 0.54347 & 142 & 120 & -22 \\
\hline YEMEN & 0.5305 & 143 & 121 & -22 \\
\hline BOTSWANA & 0.48148 & 133 & 122 & -11 \\
\hline CAMEROON & 0.34546 & 136 & 123 & -13 \\
\hline PAPUA GUINEA & 0.31476 & 132 & 124 & -8 \\
\hline TANZANIA & 0.2658 & 147 & 125 & -22 \\
\hline DJBOUTI & 0.234 & 153 & 126 & -27 \\
\hline HAITI & 0.22819 & 154 & 127 & -27 \\
\hline GHANA & 0.20495 & 129 & 128 & -1 \\
\hline MYAMNAR & 0.20217 & 119 & 129 & 10 \\
\hline ST.VINCENT & 0.19432 & 82 & 130 & 48 \\
\hline SIERRA LEONE & 0.16566 & 172 & 131 & -41 \\
\hline SOLOMON ISLAND & 0.1612 & 118 & 132 & 14 \\
\hline ANGOLA & 0.16069 & 163 & 133 & -30 \\
\hline TOGO & 0.15876 & 148 & 134 & -14 \\
\hline EQUAT. GUINEA & 0.14875 & 128 & 135 & 7 \\
\hline GAMBIA & 0.1051 & 164 & 136 & -28 \\
\hline SENEGAL & 0.09234 & 157 & 137 & -20 \\
\hline VANUATU & 0.08101 & 121 & 138 & 17 \\
\hline CENT. AFR. REP. & 0.06942 & 165 & 139 & -26 \\
\hline \multicolumn{4}{|c|}{ Mean Difference in EDI and HDI ranks } & -4.2 \\
\hline \multicolumn{4}{|c|}{ Correlation between EDI and HDI ranks } & 0.680795 \\
\hline
\end{tabular}


Table 14

Low Development Countries - Consumption Based HDI Ranks

\begin{tabular}{|c|c|c|c|c|}
\hline COUNTRY & EVN1345 & HDIR_C & EDIR & DIFFR \\
\hline BENIN & 0.0083 & 155 & 140 & -15 \\
\hline BHUTAN & 0.12397 & 151 & 141 & -10 \\
\hline GIUNEA-BISSAU & 0.54347 & 169 & 142 & -27 \\
\hline NAMIBIA & 0.5305 & 122 & 143 & 21 \\
\hline UGANDA & 1.11557 & 162 & 144 & -18 \\
\hline BURUNDI & 0.40978 & 170 & 145 & -25 \\
\hline NIGER & 0.03682 & 173 & 146 & -27 \\
\hline NICARAGUA & 0.2658 & 115 & 147 & 32 \\
\hline ETHIOPIA & 0.15876 & 171 & 148 & -23 \\
\hline MALAWI & 0.92572 & 156 & 149 & -7 \\
\hline BURKINA FASO & 0.62339 & 174 & 150 & -24 \\
\hline MOZAMBIQUE & 0.06721 & 167 & 151 & -16 \\
\hline CAMBODIA & 0.15509 & 137 & 152 & 15 \\
\hline CONGO & 0.234 & 140 & 153 & 13 \\
\hline RWANDA & 0.22819 & 159 & 154 & -5 \\
\hline CHAD & 0.06776 & 160 & 155 & -5 \\
\hline NEPAL & 0.00966 & 146 & 156 & 10 \\
\hline GUINEA & 0.09234 & 166 & 157 & -9 \\
\hline COMOROS & 0.76089 & 139 & 158 & 19 \\
\hline MALI & 0.02105 & 161 & 159 & -2 \\
\hline LAOS & 0.02822 & 141 & 160 & 19 \\
\hline MAURITANIA & 0.08246 & 152 & 161 & 9 \\
\hline GUYANA & 0.0354 & 102 & 162 & 60 \\
\hline GEORGIA & 0.16069 & 58 & 163 & 105 \\
\hline SAO TOME & 0.1051 & 116 & 164 & 48 \\
\hline PAKISTAN & 0.06942 & 138 & 165 & 27 \\
\hline SUDAN & 0.03986 & 145 & 166 & 21 \\
\hline ARMENIA & 0.0058 & 61 & 167 & 106 \\
\hline CAPE VERDE & 4.368 & 105 & 168 & 63 \\
\hline SWAZILAND & 0.06389 & 117 & 169 & 52 \\
\hline MADAGASCAR & 0.0354 & 144 & 170 & 26 \\
\hline KYRGYZSTAN & 0.00967 & 83 & 171 & 88 \\
\hline UZBEKISTAN & & 76 & 172 & 96 \\
\hline TAJIKISTAN & & 85 & 173 & 88 \\
\hline TURKMENISTAN & & 74 & 174 & 100 \\
\hline \multicolumn{4}{|c|}{ Mean Difference in EDI and HDI ranks } & 23 \\
\hline \multicolumn{4}{|c|}{ Correlation between EDI and HDI ranks } & -0.68226 \\
\hline
\end{tabular}

